\title{
Governança das corporações listadas na B3: adequação às regras de cada nível
}

\section{Governance of corporations listed on b3: suitability of each level rules}

\author{
1 Ana Caroline Maciel Blanke carol.blanke@hotmail.com \\ 2 Rosane Maria Seibert \\ 3 Raiziane Cássia Freire da Silva
}

1 Bacharela em Ciências Contábeis pela Universidade Regional Integrada do Alto Uruguai e das Missões (URI)

2 Docente Professora do Departamento de Ciências Sociais Aplicada e do Programa de Pós-Graduação em Mestrado Profissional em Gestão Estratégica de Organizações, Universidade Regional Integrada do Alto Uruguai e das Missões (URI)

3 Contadora e Mestre em Gestão Estratégica de Organizações pela Universidade Regional Integrada do Alto Uruguai e das Missões (URI)

\section{Resumo}

O presente estudo objetivou identificar se as corporações listadas no Brasil, Bolsa, Balcão (B3) demonstram seguir as regras necessárias para estarem enquadradas dentro de cada nível de governança corporativa. Trata-se de uma pesquisa descritiva e explicativa, utilizando-se de pesquisa bibliográfica, documental e de campo por meio de observação nas páginas eletrônicas de Internet de 346 corporações. Constatou-se a existência de algumas corporações em desconformidade com a totalidade das exigências da B3, necessárias para mantê-las enquadradas dentro dos respectivos níveis de governança corporativa, por exemplo, o baixo cumprimento da exigência de adesão à câmara de arbitragem do mercado. Destaca-se que este estudo não observou a totalidade de corporações listadas na B3 e nem em outros meios de divulgação. Nesse sentido, sugere-se a realização de pesquisas futuras para observar outros meios de evidenciação, como os relatórios anuais e complementares, bem como, outras corporações listadas, como também a realização de estudos semelhantes em outros países para efetuar comparações com os resultados desta pesquisa.

\section{Palavras-chave}

Governança corporativa. Mecanismos de controle. Níveis de governança corporativa.

\begin{abstract}
The present study aimed to identify whether the corporations listed in Brazil, Bolsa, Balcão (B3) demonstrate to follow the necessary rules to be framed within each level of corporate governance. This is a descriptive and explanatory research, using bibliographic, documentary and field research through observation on the Internet pages of 346 corporations. It was found that some corporations did not comply with the totality of B3's requirements, necessary to keep them within the respective levels of corporate governance, for example, the low compliance with the requirement to adhere to the market's arbitration chamber. It is noteworthy that this study did not observe the totality of corporations listed in B3 or in other media. In this sense, future research is suggested to observe other means of disclosure, such as annual and supplementary reports, as well as other listed corporations. Also, it is suggested to carry out similar studies in other countries to make comparisons with the results of this research.
\end{abstract}

\section{Keywords}

Corporate governance. Control mechanisms. Levels of corporate governance.

\section{Como você deve citar?}

BLANKE, Ana Caroline Maciel et al Governança das corporações listadas na B3: adequação às regras de cada nível. Cadernos UniFOA, Volta Redonda, n. 43, p. 97-108, agosto 2020. 


\section{INTRODUÇÃO}

A governança corporativa baseia-se em princípios e estabelece mecanismos de controle que auxiliam na gestão das corporações. Esses mecanismos e princípios servem para controlar os riscos e maximizar os retornos investidos, bem como contribuem para a sustentabilidade da corporação a longo prazo (ANDRADE \& ROSSETTI, 2014; MAZALLI; ERCOLIN, 2018).

A governança corporativa se faz presente nas bolsas de valores, como é o caso da Brasil, Bolsa, Balcão (B3). A B3 dispõe dos seguintes segmentos em que as corporações se inserem, desde que cumpram com as exigências especificas de cada um deles: Tradicional, Nível 1, Nível 2, Novo Mercado, Bovespa Mais e o Bovespa Mais Nível 2. Tais segmentos indicam o nível de qualidade da governança das corporações neles enquadrados, o que faz com que o investidor considere que essas corporações estão em conformidade com as exigências estabelecidas em cada nível, valorizando-as mais (JUNQUEIRA; SOARES; BRESSAN; BERTUCCI, 2015).

Nesse sentido é importante verificar se, de fato, as corporações enquadradas em cada nível estão atendendo e cumprindo as regras pré-estabelecidas para confirmar ao principal público interessado da B3, os investidores, a qualidade na governança dessas corporações. Desse modo, o presente estudo objetivou identificar se as corporações listadas na B3 demonstram conformidade com as exigências estabelecidas pelos segmentos nos quais se encontram enquadradas.

Na sequência, este artigo apresenta a revisão da literatura que dá suporte ao estudo empírico, os procedimentos metodológicos utilizados, os resultados da pesquisa, as considerações finais e as referências utilizadas.

\section{REVISÃO DA LITERATURA}

A governança corporativa é um sistema no qual as empresas e demais corporações são dirigidas, monitoradas e incentivadas, envolvendo os relacionamentos entre sócios, conselho de administração, diretoria, órgãos de fiscalização e controle e demais partes interessadas (IBGC, 2015). A governança tem como objetivo melhorar o desempenho da corporação envolvendo todas as partes interessadas, sejam investidores, empregados ou credores, facilitando, assim, o acesso ao mercado de capital (CVM, 2002).

A governança baseia-se em princípios que orientam o processo de boas práticas (IBGC, 2015). Conforme a Organization for Co-operation and Development (OECD, 2008), os princípios básicos de governança são: assegurar a base para uma estrutura de governança corporativa eficaz; direitos dos acionistas e funções propriedade-chave; tratamento equitativo dos acionistas; papel das partes interessadas; divulgação e transparência; responsabilidades do conselho. A partir desses princípios, o Instituto Brasileiro de Governança Corporativa (IBGC, 2015) transforma-os em quatros princípios difundidos no Brasil, conforme apresentados no quadro 1: 


\section{Quadro 1 - Princípios da governança corporativa}

\begin{tabular}{|l|l|}
\hline Princípios & Definições \\
\hline Transparência & $\begin{array}{l}\text { Todas as informações de interesse de qualquer parte interessada devem ser disponibilizadas, } \\
\text { não se restringindo aquelas atribuídas por disposições de leis ou regulamentos. }\end{array}$ \\
\hline Equidade & $\begin{array}{l}\text { Tem como característica principal o tratamento íntegro e igualitário de todas as partes } \\
\text { interessadas, não sendo aceito qualquer tipo de discriminação entre eles. }\end{array}$ \\
\hline $\begin{array}{l}\text { Prestação de } \\
\text { Contas }\end{array}$ & $\begin{array}{l}\text { Os agentes de governança devem prestar contas de sua atuação, assumindo as } \\
\text { consequências de seus atos e omissões. }\end{array}$ \\
\hline $\begin{array}{l}\text { Responsabilidade } \\
\text { Corporativa }\end{array}$ & $\begin{array}{l}\text { Os responsáveis pela governança devem cuidar da sustentabilidade das corporações, visando } \\
\text { à longevidade dela na sociedade onde está inserida, introduzindo assim, consideraçóes de } \\
\text { ordem social e ambiental na definição dos negócios e nas operações. }\end{array}$ \\
\hline
\end{tabular}

Fonte: IBGC (2015)

O sistema de governança é composto por mecanismos de controle, internos e externos, que buscam minimizar os conflitos de interesses e fortalecer a aplicação da governança nas corporações (SILVA \& SEIBERT, 2016). No quadro 2, apresenta-se os principais mecanismos de governança:

Quadro 2 - Mecanismos de controle da governança corporativa

\begin{tabular}{|c|c|c|}
\hline \multirow{11}{*}{ 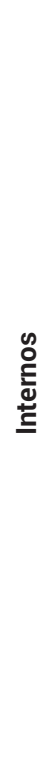 } & Mecanismos & Características \\
\hline & Sistema de Remuneração & Alinha-se com os interesses da companhia e de seus acionistas. \\
\hline & Assembleia-geral & $\begin{array}{l}\text { É órgão superior da corporação. Possui pleno poder para tomada de decisão, seja } \\
\text { para desenvolvimento quanto para defesa, quando for necessário. }\end{array}$ \\
\hline & Estrutura de Propriedade & $\begin{array}{l}\text { Referente à concentração acionária e à aproximação da atuação de investidores } \\
\text { institucionais. }\end{array}$ \\
\hline & Conselho de Administração & Deve ser ativo e atuar com independência. \\
\hline & $\begin{array}{l}\text { Controle de Compliance e Gestão } \\
\text { de Riscos Corporativos }\end{array}$ & $\begin{array}{l}\text { Deve assegurar que os procedimentos da corporação estão de acordo com as } \\
\text { boas práticas, leis, regulamentos e normas. }\end{array}$ \\
\hline & Constituição de Sociedades & $\begin{array}{l}\text { No acordo de sócios, deve ser previsto a forma de apuração de haveres, inclusive } \\
\text { quanto aos bens intangíveis, evitando-se contingências no futuro. }\end{array}$ \\
\hline & Conselho Fiscal & $\begin{array}{l}\text { Deve fiscalizar a gestão da corporação, os atos de seus administradores e dos } \\
\text { cumprimentos dos deveres legais e estatutários. }\end{array}$ \\
\hline & Comitê de Auditoria & $\begin{array}{l}\text { Deve ter autoridade para investigar qualquer assunto de sua responsabilidade. } \\
\text { Pode recorrer a um conselho profissional externo e, caso seja necessário, } \\
\text { convidar peritos de fora. }\end{array}$ \\
\hline & Auditoria Interna & $\begin{array}{l}\text { Verifica a adequação e a eficácia do gerenciamento de riscos operacionais em } \\
\text { relação a exigências internas e externas. }\end{array}$ \\
\hline & Auditoria Independente & $\begin{array}{l}\text { Tem a finalidade de examinar as demonstrações contábeis para garantir a } \\
\text { veracidade das informações. }\end{array}$ \\
\hline \multirow{5}{*}{ : } & Estrutura de capital & $\begin{array}{l}\text { Alavancagem e necessidade de capitais induzindo compensação do risco } \\
\text { assumido e o alcance do ponto ótimo de estrutura de capital. }\end{array}$ \\
\hline & $\begin{array}{l}\text { Fiscalização dos agentes de } \\
\text { mercado }\end{array}$ & $\begin{array}{l}\text { Trata-se de analistas externos, agências de classificação de risco e ratings de } \\
\text { governança corporativas, exigindo maior nível de transparência e controle por } \\
\text { parte das corporações. }\end{array}$ \\
\hline & Proteção legal aos investidores & Trata-se de leis e normas que visam à equidade e redução conflitos de interesses. \\
\hline & Aquisição Hostil & $\begin{array}{l}\text { Medo da perda de cargo pelos executivos por meio de uma aquisição hostil de } \\
\text { ações, levando à integralização de capital por um novo sócio e de informações de } \\
\text { controles internos, a fim de impedir tal fato. }\end{array}$ \\
\hline & Grau de competição & $\begin{array}{l}\text { Relacionado à competitividade do mercado de trabalho dos executivos e o risco } \\
\text { de perda do emprego por perda da eficiência e resultados. }\end{array}$ \\
\hline
\end{tabular}


Portanto, para que o sistema de governança seja eficiente, é importante que a corporação disponha de mecanismos de controle, assegurando a redução da assimetria de informação entre as partes interessadas, bem como tomadas de decisões em prol da sustentabilidade da corporação (DUARTE et al., 2019).

No Brasil, a governança corporativa surgiu em resposta ao movimento pelas boas práticas, já difundida internacionalmente, e pela globalização, exigindo a modernização das corporações, para assim, também tornar o mercado mais atraente (IBGC, $n$. d.). De modo a incentivar a adoção das boas práticas de governança pelas corporações que negociam na bolsa de valores brasileira, no ano de 2000, a Bolsa de Valores, Mercadorias e Futuros de São Paulo (BM\&FBovespa), atualmente conhecida como Brasil, Bolsa, Balcão (B3), instituiu segmentos diferenciados, representando níveis distintos de governança (SILVA \& SEIBERT, 2015; SILVA; ARAÚJO; MONTE, 2018).

Cada um dos segmentos, dispõe de exigências a serem cumpridas pelas corporações, visando garantir os direitos dos acionistas e a transparência para as partes interessadas, reduzindo os riscos dos investidores (SILVA et al., 2016), além de beneficiar as corporações no que diz respeito ao aumento do valor de mercado, aumento da liquidez, melhoria da estrutura de capital, dentro outros (SILVA et al., 2018). São eles:

Quadro 3 - Segmentos do Brasil, Bolsa, Balcão

\begin{tabular}{|l|l|}
\hline Segmentos & Características \\
\hline Tradicional & Nível mais básico, não possuindo regras diferenciadas de governança. \\
\hline Nível 1 & $\begin{array}{l}\text { A corporação deverá adotar práticas que beneficiem a transparência e o acesso às informações pelos } \\
\text { seus investidores, que vão além das exigidas por lei. O free float mínimo é de 25\%. }\end{array}$ \\
\hline Nível 2 & $\begin{array}{l}\text { Possuem o direito de manter ações preferenciais (PN). Além de cumprir com as exigências estabelecidas } \\
\text { no Nível 1, devem também observar a limitação de voto; o mandato unificado de máximo de dois anos no } \\
\text { Conselho de Administração (CA); a existência de conselheiro(s) independente(s); vedado a acumulação } \\
\text { de cargos de presidente do CA e de diretor presidente ou principal executivo da corporação. }\end{array}$ \\
\hline Novo Mercado & $\begin{array}{l}\text { Somente podem emitir ações ordinárias e o direito de tag along é de 100\%. Além de cumprir das } \\
\text { exigências do nível 1 e 2, o CA, deve contar com 20\% de membros independentes e os relatórios } \\
\text { financeiros anuais devem seguir o padrão internacional. }\end{array}$ \\
\hline $\begin{array}{l}\text { Bovespa Mais } \\
\text { Nível 2 }\end{array}$ & $\begin{array}{l}\text { Possuem o direito de manter ações preferenciais (PN) com direito a voto em caso de transformação, } \\
\text { incorporação, fusão ou cisão da corporação; contratos entre o acionista controlador e a corporação, } \\
\text { sempre que essas decisões estiverem sujeitas à aprovação na assembleia de acionistas. }\end{array}$ \\
\hline Bovespa Mais & $\begin{array}{l}\text { Objetiva fomentar o crescimento de pequenas e médias corporações através do mercado de capitais. } \\
\text { Permite efetuar a listagem tendo até } 7 \text { anos para realizar o IPO, com isenção de taxa de análise para } \\
\text { listagem de emissores e desconto regressivo na anuidade, sendo 100\% no primeiro ano. O capital social } \\
\text { deverá ser exclusivo em ações ordinárias, exceto em desestatização. }\end{array}$ \\
\hline
\end{tabular}

Fonte: B3, s. d.

Cabe destacar que esses segmentos estão em constante atualização em consonância com as boas práticas de governança adotadas no mercado internacional $(B 3,2016)$. 0 quadro 4 expõe as diferenças entre eles: 
Quadro 4 - Comparativo dos segmentos de níveis de governança da B3

\begin{tabular}{|c|c|c|c|c|c|c|}
\hline & $\begin{array}{c}\text { Bovespa } \\
\text { Mais }\end{array}$ & $\begin{array}{c}\begin{array}{c}\text { Bovespa } \\
\text { Mais }\end{array} \\
\text { Nível } 2\end{array}$ & Novo Mercado & Nível 2 & Nível 1 & Tradicional \\
\hline Capital Social & $\begin{array}{l}\text { Somente } \\
\text { ações ON }\end{array}$ & Ações ON e PN & Somente ações ON & $\begin{array}{l}\text { Ações ON e PN } \\
\text { (com direitos } \\
\text { adicionais) }\end{array}$ & $\begin{array}{l}\text { Ações ON e } \\
\text { PN (conforme } \\
\text { legislação) }\end{array}$ & $\begin{array}{l}\text { Ações } \\
\text { ON e PN } \\
\text { (conforme } \\
\text { legislação) }\end{array}$ \\
\hline $\begin{array}{l}\text { Percentual } \\
\text { mínimo free } \\
\text { float }\end{array}$ & $\begin{array}{l}25 \% \text { a partir } \\
\text { do } 7^{\circ} \text { ano de } \\
\text { listagem }\end{array}$ & $\begin{array}{l}25 \% \text { a partir } \\
\text { do } 7^{\circ} \text { ano de } \\
\text { listagem }\end{array}$ & $\begin{array}{l}25 \% \text { ou } 15 \% \text {, caso o } \\
\text { average daily trading } \\
\text { volume seja superior a } \mathrm{R} \$ \\
25 \text { milhões }\end{array}$ & $25 \%$ & $25 \%$ & $\begin{array}{l}\text { Não há regra } \\
\text { específica }\end{array}$ \\
\hline $\begin{array}{l}\text { Ofertas } \\
\text { Públicas de } \\
\text { Distribuição de } \\
\text { ações }\end{array}$ & $\begin{array}{l}\text { Não há regra } \\
\text { específica }\end{array}$ & $\begin{array}{l}\text { Não há regra } \\
\text { específica }\end{array}$ & $\begin{array}{l}\text { Esforços de dispersão } \\
\text { acionária, exceto para } \\
\text { ofertas ICVM } 476\end{array}$ & $\begin{array}{l}\text { Esforços de } \\
\text { dispersão } \\
\text { acionária }\end{array}$ & $\begin{array}{l}\text { Esforços de } \\
\text { dispersão } \\
\text { acionária }\end{array}$ & $\begin{array}{l}\text { Não há regra } \\
\text { específica }\end{array}$ \\
\hline $\begin{array}{l}\text { Vedação a } \\
\text { disposições } \\
\text { estatutárias }\end{array}$ & $\begin{array}{l}\text { Quórum } \\
\text { qualificado } \\
\text { e "cláusulas } \\
\text { pétreas" }\end{array}$ & $\begin{array}{l}\text { Quórum } \\
\text { qualificado } \\
\text { e "cláusulas } \\
\text { pétreas" }\end{array}$ & $\begin{array}{l}\text { Limitação de voto inferior } \\
\text { a } 5 \% \text { do capital, quórum } \\
\text { qualificado e "cláusulas } \\
\text { pétreas" }\end{array}$ & $\begin{array}{l}\text { Limitação de } \\
\text { voto inferior a } \\
5 \% \text { do capital, } \\
\text { quórum } \\
\text { qualificado } \\
\text { e "cláusulas } \\
\text { pétreas" }\end{array}$ & $\begin{array}{l}\text { Não há regra } \\
\text { específica }\end{array}$ & $\begin{array}{l}\text { Não há regra } \\
\text { específica }\end{array}$ \\
\hline $\begin{array}{l}\text { Composição } \\
\text { do CA }\end{array}$ & $\begin{array}{l}\text { Mínimo } 3 \\
\text { membros } \\
\text { com mandato } \\
\text { unificado de } \\
\text { até } 2 \text { anos }\end{array}$ & $\begin{array}{l}\text { Mínimo } 3 \\
\text { membros } \\
\text { com mandato } \\
\text { unificado de } \\
\text { até } 2 \text { anos }\end{array}$ & $\begin{array}{l}\text { Mínimo } 3 \text { membros com, } \\
\text { pelo menos, } 2 \text { ou } 20 \% \\
\text { independentes, com } \\
\text { mandato unificado de até } \\
2 \text { anos }\end{array}$ & $\begin{array}{l}\text { Mínimo } 5 \\
\text { membros, } \\
\text { com, pelo } \\
\text { menos, } 20 \% \\
\text { independentes } \\
\text { com mandato } \\
\text { unificado de } \\
\text { até } 2 \text { anos } \\
\end{array}$ & $\begin{array}{l}\text { Mínimo } 3 \\
\text { membros, } \\
\text { com mandato } \\
\text { unificado de } \\
\text { até } 2 \text { anos }\end{array}$ & $\begin{array}{l}\text { Mínimo de } 3 \\
\text { membros }\end{array}$ \\
\hline $\begin{array}{l}\text { Vedação à } \\
\text { acumulação de } \\
\text { cargos }\end{array}$ & $\begin{array}{l}\text { Não há regra } \\
\text { específica }\end{array}$ & $\begin{array}{l}\text { Não há Regra } \\
\text { específica }\end{array}$ & $\begin{array}{l}\text { Presidente do CA e } \\
\text { diretor presidente ou } \\
\text { principal executivo. Em } \\
\text { caso de vacância que } \\
\text { resulte na acumulação } \\
\text { dos cargos, são } \\
\text { obrigatórias determinadas } \\
\text { divulgações. }\end{array}$ & $\begin{array}{l}\text { Presidente do } \\
\text { CA e diretor } \\
\text { presidente } \\
\text { ou principal } \\
\text { executivo } \\
\text { (carência de } 3 \\
\text { anos a partir } \\
\text { da adesão). } \\
\end{array}$ & $\begin{array}{l}\text { Presidente do } \\
\text { CA e diretor } \\
\text { presidente } \\
\text { ou principal } \\
\text { executivo } \\
\text { (carência de } 3 \\
\text { anos a partir } \\
\text { da adesão) } \\
\end{array}$ & $\begin{array}{l}\text { Não há regra } \\
\text { específica }\end{array}$ \\
\hline $\begin{array}{l}\text { Obrigação do } \\
\text { CA }\end{array}$ & $\begin{array}{l}\text { Não há regra } \\
\text { específica }\end{array}$ & $\begin{array}{l}\text { Não há regra } \\
\text { específica }\end{array}$ & $\begin{array}{l}\text { Manifestação sobre } \\
\text { qualquer oferta pública } \\
\text { de aquisição de ações de } \\
\text { emissão da corporação }\end{array}$ & $\begin{array}{l}\text { Manifestação } \\
\text { sobre qualquer } \\
\text { oferta pública } \\
\text { de aquisição } \\
\text { de ações de } \\
\text { emissão da } \\
\text { corporação }\end{array}$ & $\begin{array}{l}\text { Não há regra } \\
\text { específica }\end{array}$ & $\begin{array}{l}\text { Não há } \\
\text { Regra } \\
\text { específica }\end{array}$ \\
\hline $\begin{array}{l}\text { Demonstrações } \\
\text { financeiras }\end{array}$ & $\begin{array}{l}\text { Conforme } \\
\text { legislação }\end{array}$ & $\begin{array}{l}\text { Conforme } \\
\text { legislação }\end{array}$ & Conforme legislação & $\begin{array}{l}\text { Traduzidas } \\
\text { para o inglês }\end{array}$ & $\begin{array}{l}\text { Conforme } \\
\text { legislação }\end{array}$ & $\begin{array}{l}\text { Conforme } \\
\text { legislação }\end{array}$ \\
\hline $\begin{array}{l}\text { Informações } \\
\text { em inglês, } \\
\text { simultâneas à } \\
\text { divulgação em } \\
\text { português }\end{array}$ & $\begin{array}{l}\text { Não há regra } \\
\text { específica }\end{array}$ & $\begin{array}{l}\text { Não há regra } \\
\text { específica }\end{array}$ & $\begin{array}{l}\text { Fatos relevantes, } \\
\text { informações sobre } \\
\text { proventos e press release } \\
\text { de resultados }\end{array}$ & $\begin{array}{l}\text { Não há regra } \\
\text { específica, } \\
\text { além das DFs }\end{array}$ & $\begin{array}{l}\text { Não há regra } \\
\text { específica }\end{array}$ & $\begin{array}{l}\text { Não há regra } \\
\text { específica }\end{array}$ \\
\hline $\begin{array}{l}\text { Reunião } \\
\text { pública anual }\end{array}$ & Facultativa & Facultativa & $\begin{array}{l}\text { Realização, em até } 5 \text { dias } \\
\text { úteis após a divulgação } \\
\text { de resultados trimestrais } \\
\text { ou das demonstrações } \\
\text { financeiras, de } \\
\text { apresentação pública } \\
\text { sobre as informações } \\
\text { divulgadas }\end{array}$ & $\begin{array}{l}\text { Obrigatória } \\
\text { (presencial) }\end{array}$ & $\begin{array}{l}\text { Obrigatória } \\
\text { (presencial) }\end{array}$ & Facultativa \\
\hline $\begin{array}{l}\text { Calendário } \\
\text { de eventos } \\
\text { corporativos }\end{array}$ & Obrigatório & Obrigatório & Obrigatório & Obrigatório & Obrigatório & Facultativo \\
\hline
\end{tabular}




\begin{tabular}{|c|c|c|c|c|c|c|}
\hline & $\begin{array}{l}\text { Bovespa } \\
\text { Mais }\end{array}$ & $\begin{array}{c}\text { Bovespa } \\
\text { Mais } \\
\text { Nível } 2\end{array}$ & Novo Mercado & Nível 2 & Nível 1 & Tradicional \\
\hline $\begin{array}{l}\text { Divulgação } \\
\text { adicional de } \\
\text { informações }\end{array}$ & $\begin{array}{l}\text { Política de } \\
\text { negociação } \\
\text { de valores } \\
\text { mobiliários }\end{array}$ & $\begin{array}{l}\text { Política de } \\
\text { negociação } \\
\text { de valores } \\
\text { mobiliários }\end{array}$ & $\begin{array}{l}\text { Regimentos do CA, } \\
\text { comitês e do conselho } \\
\text { fiscal; código de conduta; } \\
\text { políticas de remuneração, } \\
\text { indicação de membros } \\
\text { do CA, comitês e diretoria } \\
\text { estatutária; gerenciamento } \\
\text { de riscos; transação com } \\
\text { partes relacionadas; } \\
\text { negociação de valores } \\
\text { mobiliários. Divulgação } \\
\text { anual de relatório } \\
\text { resumido do comitê de } \\
\text { auditoria ou trimestral de } \\
\text { ata de reunião do CA com } \\
\text { o reporte do comitê de } \\
\text { auditoria }\end{array}$ & $\begin{array}{l}\text { Política de } \\
\text { negociação } \\
\text { de valores } \\
\text { mobiliários } \\
\text { e código de } \\
\text { conduta }\end{array}$ & $\begin{array}{l}\text { Política de } \\
\text { negociação } \\
\text { de valores } \\
\text { mobiliários } \\
\text { e código de } \\
\text { conduta }\end{array}$ & Não há regra \\
\hline $\begin{array}{l}\text { Concessão de } \\
\text { Tag Along }\end{array}$ & $\begin{array}{l}100 \% \text { para } \\
\text { ações ON }\end{array}$ & $\begin{array}{l}\text { 100\% para } \\
\text { ações ON e PN }\end{array}$ & 100\% para ações ON & $\begin{array}{l}\text { 100\% para } \\
\text { ações ON e PN }\end{array}$ & $\begin{array}{l}\text { 80\% para } \\
\text { ações ON } \\
\text { (conforme } \\
\text { legislação) }\end{array}$ & $\begin{array}{l}\text { 80\% para } \\
\text { ações ON } \\
\text { (conforme } \\
\text { legislação) }\end{array}$ \\
\hline $\begin{array}{l}\text { Saída do } \\
\text { segmento / } \\
\text { Oferta Pública } \\
\text { de Aquisição } \\
\text { de Ações (OPA) }\end{array}$ & $\begin{array}{l}\text { OPA, no } \\
\text { mínimo, } \\
\text { pelo valor } \\
\text { econômico } \\
\text { em caso de } \\
\text { cancelamento } \\
\text { de registro } \\
\text { ou saída do } \\
\text { segmento, } \\
\text { exceto se } \\
\text { houver } \\
\text { migração para } \\
\text { Novo Mercado }\end{array}$ & $\begin{array}{l}\text { OPA, no } \\
\text { mínimo, } \\
\text { pelo valor } \\
\text { econômico } \\
\text { em caso de } \\
\text { cancelamento } \\
\text { de registro } \\
\text { ou saída do } \\
\text { segmento, } \\
\text { exceto se } \\
\text { houver } \\
\text { migração para } \\
\text { Novo Mercado } \\
\text { ou Nível } 2\end{array}$ & $\begin{array}{l}\text { OPA por preço justo, com } \\
\text { quórum de aceitação ou } \\
\text { concordância com a saída } \\
\text { do segmento de mais } \\
\text { de } 1 / 3 \text { dos titulares das } \\
\text { ações em circulação ou } \\
\text { percentual maior previsto } \\
\text { no Estatuto Social }\end{array}$ & $\begin{array}{l}\text { OPA, no } \\
\text { mínimo, } \\
\text { pelo valor } \\
\text { econômico } \\
\text { em caso de } \\
\text { cancelamento } \\
\text { de registro } \\
\text { ou saída do } \\
\text { segmento, } \\
\text { exceto se } \\
\text { houver } \\
\text { migração para } \\
\text { Novo Mercado }\end{array}$ & Não aplicável & $\begin{array}{l}\text { Não } \\
\text { aplicável }\end{array}$ \\
\hline $\begin{array}{l}\text { Adesão à } \\
\text { Câmara de } \\
\text { Arbitragem do } \\
\text { Mercado }\end{array}$ & Obrigatória & Obrigatória & Obrigatória & Obrigatória & Facultativa & Facultativa \\
\hline $\begin{array}{l}\text { Comitê de } \\
\text { Auditoria }\end{array}$ & Facultativo & Facultativo & $\begin{array}{l}\text { Obrigatória, estatutário ou } \\
\text { não estatutário }\end{array}$ & Facultativo & Facultativo & Facultativo \\
\hline $\begin{array}{l}\text { Auditoria } \\
\text { interna }\end{array}$ & Facultativa & Facultativa & Obrigatória & Facultativa & Facultativa & Facultativa \\
\hline Compliance & Facultativo & Facultativo & $\begin{array}{l}\text { Obrigatória, sendo vedada } \\
\text { a acumulação com } \\
\text { atividades operacionais }\end{array}$ & Facultativo & Facultativo & Facultativo \\
\hline
\end{tabular}

Fonte: B3, s. d.

A adesão aos segmentos é ato voluntário da corporação e representa o compromisso com a prática de governança para além do que a legislação já determina (JUNQUEIRA et al., 2015; SILVA et al., 2016). No entanto, a autorização cedida, por prazo indeterminado, à corporação para pertencerem a esses segmentos não implica qualquer apreciação sobre a mesma, sendo os administradores os responsáveis pela veracidade, precisão e completude de todas as informações prestadas a B3 e pela autenticidade dos documentos a ela enviados (B3, 2016). 


\section{PROCEDIMENTOS METODOLÓGICOS}

O estudo é classificado como descritivo e explicativo (VERGARA, 2016). Utilizou-se de pesquisa bibliográfica, documental e de campo, por meio de observação, para alcançar os objetivos da pesquisa. Analisou-se o regulamento do segmento tradicional, nível 1, nível 2, novo mercado, Bovespa mais e Bovespa mais nível 2, disponíveis na página eletrônica de internet da B3. Na sequência, realizou-se observação não participante nas páginas eletrônicas publicadas na internet das corporações para identificar o cumprimento desses regulamentos.

A pesquisa foi realizada no período de março a maio de 2017 nas corporações listadas nos segmentos estudados e que disponibilizam informações direcionadas aos investidores e demais stakeholders por meio de suas páginas eletrônicas de Internet, o que resultou em uma amostra de 346 corporações sendo: 49 listadas no segmento Tradicional, 33 listadas no segmento Nível 1, 27 listadas no segmento Nível 2, 139 listadas no Novo Mercado, 39 listadas no segmento Bovespa Mais e 59 listadas no segmento Bovespa Mais Nível 2. Destaca-se que as corporações de cada segmento, componentes da amostra, tem como base o início do ano de 2017.

Para o levantamento das informações utilizou-se uma planilha de Excel na qual foram dispostos os principais tópicos dos regulamentos e atribuído peso um ou zero, dependendo da verificação do cumprimento pela corporação, que foi realizada por meio de análise de conteúdo (BARDIN, 1977), classificando cada informação pelo conteúdo compatível com a regra estabelecida pela B3. No final, somou-se os pesos para encontrar o percentual de corporações que demonstram a conformidade com as exigências dos segmentos nos quais estão listadas.

\section{APRESENTAÇÃO E DISCUSSÃO DOS RESULTADOS}

As evidências encontradas no levantamento realizado nas páginas eletrônicas de Internet das corporações estão apresentadas no Tabela 1. Na primeira coluna, estão descritos os tópicos do regulamento e, nas demais colunas, a quantidade de corporações que demonstram atendê-las, de acordo com o seu segmento: 
Quadro 5 - Principais exigências dos segmentos versus quantidade de corporações em conformidade

\begin{tabular}{|c|c|c|c|c|c|c|}
\hline & $\begin{array}{l}\bar{\pi} \\
\text { 은 } \\
\text { 음 } \\
\text { 힌 }\end{array}$ & 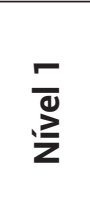 & $\frac{N}{\grave{D}}$ & 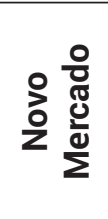 & 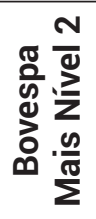 & 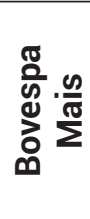 \\
\hline Características das Ações Emitidas & 49 & 33 & 27 & 136 & 58 & 39 \\
\hline Percentual mínimo free float & 49 & 31 & 24 & 129 & 59 & 39 \\
\hline Distribuições Públicas de Ações & 49 & 33 & 26 & 137 & 59 & 39 \\
\hline Vedação e Disposições estatutárias & 49 & 32 & 26 & 136 & 49 & 37 \\
\hline Composição do CA & 49 & 33 & 27 & 130 & 59 & 38 \\
\hline Vedação e Acumulação de Cargos & 49 & 32 & 26 & 135 & 59 & 39 \\
\hline Obrigação do CA & 49 & 33 & 27 & 139 & 59 & 39 \\
\hline Demonstrações Financeiras & 49 & 33 & 26 & 138 & 59 & 39 \\
\hline Reunião Pública Anual & 49 & 33 & 23 & 136 & 58 & 39 \\
\hline Calendário de Eventos & 48 & 31 & 23 & 136 & 20 & 24 \\
\hline Divulgação Adicional de Informações & 49 & 33 & 26 & 139 & 58 & 39 \\
\hline Concessão de Tag Along & 49 & 33 & 27 & 139 & 59 & 39 \\
\hline Oferta Púbica de Aquisição de Ações pelo Valor Econômico & 27 & 31 & 26 & 139 & 56 & 39 \\
\hline Adesão à Câmara de Arbitragem do Mercado & 49 & 32 & 21 & 134 & 9 & 16 \\
\hline Média de Corporações & 47,36 & 32,36 & 25,36 & 135,93 & 51,5 & 36,14 \\
\hline Percentual de Corporações (\%) & 96,65 & 98,06 & 93,93 & 97,79 & 87,3 & 92,67 \\
\hline
\end{tabular}

Fonte: Dados da pesquisa.

Percebe-se que a maior parte das corporações demonstram sua conformidade com as exigências dos segmentos em que estão listadas. O segmento com percentual mais próximo a 100\% é o Nível 1, no qual $98,06 \%$ das corporações demonstram cumprir os 14 tópicos do regulamento pesquisado em suas páginas eletrônicas de Internet. 0 segmento Bovespa Mais Nível 2 foi o que apresentou menor percentual, $87,3 \%$, em virtude do baixo cumprimento da exigência de adesão à câmara de arbitragem do mercado.

Cabe destacar que essas regras não são exigidas em todos os segmentos, tornando-se voluntário o cumprimento pela corporação. É o caso daquelas que estão listadas no nível tradicional, em que a maioria dessas exigências são facultativas (B3, s. d.) e, no entanto, são seguidas por $96,65 \%$ das corporações. Esse fato demonstra os esforços para conquistar ou aumentar a confiança do investidor na corporação, por meio da adoção de boas práticas de governança. Por outro lado, nos segmentos Nível 2 e Novo Mercado todas as regras são obrigatórias e, ainda assim, observou-se a inconformidade de algumas corporações listadas nele, o que compromete a legitimação da corporação perante seus públicos e, também, como merecedoras do enquadramento nesses segmentos.

Com relação aos itens exigidos em cada nível, em apenas uma corporação listada no segmento Bovespa Mais Nível 2 e em outras três listadas no Novo Mercado não foi evidenciado, em suas páginas eletrônicas da Internet, as características das ações emitidas, ou seja, se emitem ações preferenciais (PN) e/ou ações ordinárias (ON). Já as informações sobre o percentual mínimo free float, não foram evidenciados em duas corporações listadas no segmento Nível 1, em três corporações listadas no segmento Nível 2 e em 10 corporações listadas no Novo Mercado. Ressalta-se que tal item é facultativo apenas para o segmento Tradicional. 
Quanto às distribuições públicas de ações, medida que visa garantir o acesso para todos os investidores interessados (SILVA, 2012), apenas não foi encontrada na página eletrônica de uma corporação do segmento Nível 2 e em duas corporações do segmento Novo Mercado. 0 item vedação e disposições estatutárias em que, ressalvados em casos de exigência legal ou regulamentação aplicável, as corporações não poderão estabelecer, em seus estatutos, quórum qualificado para a liberação de matérias e impedir o exercício de voto favorável ou que imponham ônus aos acionistas que votarem favoravelmente à supressão ou alteração de cláusulas (ANDRADE \& ROSSETTI, 2014), foi demonstrado por todas as corporações do segmentos tradicionais, mesmo não havendo regra específica para esse segmento, diferentemente dos demais segmentos em que algumas corporações não evidenciaram tal item.

O conselho de administração é essencial para a prática da boa governança das corporações (ANDRADE; ROSSETI, 2014; MAZALLI; ERCOLIN, 2018) e, para as corporações listadas na B3, a composição do conselho deve obedecer a critérios de acordo com o segmento em que estiverem listadas. Esse item não foi evidenciado em uma corporação do segmento Bovespa Mais e em nove corporações do segmento Novo Mercado.

Quanto à obrigação do conselho, Cadbury (1992) destaca que cabe aos conselheiros incluir as ideias e os objetivos estratégicos da organização, em prática, fiscalizar e gerar relatórios para os acionistas. Esse foi um dos dois itens evidenciado em todas as páginas eletrônicas das corporações pesquisadas. 0 outro item foi a concessão de tag along, já exigida pela Lei das S. A. e que a B3 adotou para obrigar as corporações a assegurar o preço mínimo de $80 \%$ aos acionistas minoritários (ANDRADE; ROSSETTI, 2014; MARINHO, 2018).

A vedação e acumulação de cargos é uma exigência das boas práticas de governança, motivado pelo papel desempenhado pelo conselho de administração dentro da corporação (ANDRADE; ROSSETTI, 2014; MAZALLI; ERCOLIN, 2018), no entanto, a observância dessa exigência não foi observada em uma corporação listada no Nível 1, em outra listada no Nível 2 e em quatro listadas no Novo Mercado.

A exigência da apresentação das demonstrações financeiras é fundamentada em dois princípios da governança: transparência e prestação de contas (IBGC, 2015; OECD, 2008). Assim, todas as corporações devem apresentar suas demonstrações em cumprimento a tais princípios. Porém, em uma corporação pertencente ao segmento Nível 2 e outra listada no segmento Novo Mercado, as demonstrações financeiras não foram evidenciadas.

O item reunião pública anual não foi evidenciado em quatro corporações do segmento Nível 2, três corporações do segmento Novo Mercado e uma listada no Bovespa Mais Nível 2. Destaca-se que, uma vez por ano, as partes interessadas deverão ser reunidas para conhecimento da real situação econômica da corporação e de seus projetos (SILVA, 2012). Já o calendário de eventos, item opcional apenas para o segmento Tradicional, não foi disponibilizado por todas as corporações dos demais segmentos. O segmento com menos divulgação por parte das corporações foi o Bovespa Mais Nível 2, não tendo sido evidenciado em trinta e cinco de suas corporações.

As corporações deverão divulgar demais informações para B3, como a política de negociação de valores mobiliários e códigos de conduta $(B 3,2016)$. Essa exigência é facultativa apenas paras as corporações listadas no segmento Tradicional, porém, todas as corporações desse segmento evidenciaram tal item. Somente duas corporações, uma do segmento Nível 2 e outra do segmento Bovespa Mais Nível 2, não evidenciou este item em suas respectivas páginas eletrônicas da Internet. 
Quanto à oferta pública de aquisição de ações, há regra instituídas para os segmentos Novo Mercado, Nível 1 e Nível 2, porém o único segmento que teve o item evidenciado por todas as corporações foi o Novo Mercado. Quanto à adesão à câmara de arbitragem do mercado, o único segmento em que todas as corporações evidenciaram essa informação foi o Tradicional. Ressalta-se a importância da Câmara de Arbitragem do Mercado devido a seu papel para resolução de disputas societárias e do mercado de capitais (SILVA, 2012; MATTOS; RENZETTI, 2018). Ressalta-se que para o segmento Tradicional e Nível 1, esse item é opcional.

Destaca-se que, de maneira geral, a maioria das corporações demonstram serem cumpridoras das regras estabelecidas pela B3, conforme o segmento em que se encontram enquadradas. É importante o cumprimento do estabelecido para cada nível dado, pois essa informação pode ser utilizada pelo investidor, quando escolher o seu investimento (MORCK, 2005). 0 investidor legitima a organização (SUCHMAN, 1995) pela informação disponibilizada no site da B3 que está avalizando a qualidade na sua governança (B3, s. d.).

A seguir se apresentam as considerações finais do artigo.

\section{CONSIDERAÇÕES FINAIS}

Considerando as corporações que negociam suas ações na B3 e que são enquadradas em níveis de governança corporativa, julgou-se relevante pesquisar sobre a evidenciação do cumprimento dos requisitos necessários para tal enquadramento. Portanto, a pesquisa objetivou identificar se as corporações listadas na B3 demonstram seguir as regras necessárias para estarem enquadradas dentro de cada nível de governança corporativa.

Para alcançar o objetivo da pesquisa, procedeu-se investigação bibliográfica, documental e de campo. Analisou-se qualitativamente as evidências, por meio de análise de conteúdo, de 346 corporações que negociam suas ações no mercado padrão da B3 e que têm páginas eletrônicas publicadas na Internet.

Os resultados mostram que, no nível tradicional, $96,65 \%$ das corporações listadas demonstram seguir as regras exigidas. No nível 1 de governança corporativa, foi identificado que $98,06 \%$ das corporações demonstram seguir as regras exigidas para estarem enquadradas. Já no nível 2, constatou-se que $93,93 \%$ das corporações listadas nesse segmento demonstram seguir as regras estabelecidas pela B3. No novo mercado, verificou-se que $97,79 \%$ seguem as regras exigidas para estarem enquadradas nesse segmento de listagem. No segmento Bovespa Mais Nível 2, apenas $87,30 \%$ das corporações seguem as regras exigidas pela B3, enquanto que no Bovespa Mais $92,67 \%$ estão em conformidade. Logo, a maioria das corporações evidenciam o atendimento às exigências para o enquadramento nos níveis de governança corporativa definidos pela B3.

Na pesquisa, observou-se somente as páginas eletrônicas da Internet das corporações que compõem a amostra. Assim, não se pode afirmar que aquelas que não evidenciam o cumprimento dos requisitos para o enquadramento não os estejam de fato cumprindo. Logo, sugere-se novas pesquisas observando outros meios de evidenciação, por exemplo, relatórios anuais e complementares.

Também se analisou apenas corporações que negociam suas ações no mercado padrão na B3, podendo haver pesquisas futuras que analisem os requisitos estabelecidos por outras bolsas de valores no mundo versus as corporações que negociam suas ações nesses mercados, possibilitando comparações com os resultados obtidos nesta pesquisa. 
Por fım, as contribuições desta pesquisa são relativas à divulgação do cumprimento dos requisitos para o enquadramento dos níveis de governança corporativa da B3. Isso pode servir para as corporações e para a B3 ajustar a evidenciação do cumprimento dos requisitos, possibilitando maior segurança e confiança aos investidores quanto à qualidade da governança das corporações.

\section{REFERÊNCIAS}

ANDRADE, A.; ROSSETTI, J. P. Governança Corporativa: fundamentos, desenvolvimento e tendências. 7. ed. São Paulo: Editora Atlas, 2014.

BARDIN, L. Análise de conteúdo. Lisboa: Edições 70, 1977.

BM\&FBOVESPA. Segmentos de listagem. Disponível em: http://www.bmfbovespa.com.br. Acesso em: 20 mar. 2017.

BRASIL, BOLSA, BALCÃO. Sobre segmentos de listagem. Disponível em: http://www.b3.com.br/ pt_br/produtos-e-servicos/solucoes-para-emissores/segmentos-de-listagem/sobre-segmentos-delistagem/. Acesso em: 20 jul. 2019

CADBURY COMMITTEE. The report of the committee on financial aspects of corporate governance. Londres: Cadbury Committee, Dec. 1992. Disponível em: https://ecgi.global > download > file > fid. Acesso em: 23 out. 2017.

CVM - Comissão de Valores Mobiliários. Recomendações da CVM sobre Governança Corporativa. 2002. Disponível em: http://www.cvm.gov.br/export/sites/cvm/decisoes/anexos/0001/3935.pdf. Acesso em: 23 out. 2017.

DUARTE, D. L.; ARAÚJO, F. B. B.; PEIXOTO, F. M.; \& BARBOZA, F. L. M. Disclosure de governança corporativa e o nível de Internacionalização das empresas no mercado de capitais brasileiro. Advances in Scientific \& Applied Accounting, v. 12, n. 3, 2019.

JUNQUEIRA, L. R.; SOARES, C. H.; BRESSAN, A. A.; BERTUCCI, L. A. Impactos da adesão aos níveis diferenciados de governança corporativa sobre a estrutura de capital das empresas brasileiras. Revista de Administração da UFSM, v. 10, n. 3, p. 420-436, 2017.

IBGC. Instituto Brasileiro de Governança Corporativa. Códigos das Melhores Práticas de Governança Corporativa. 5. ed. São Paulo, 2015

IBGC. Instituto Brasileiro de Governança Corporativa. Governança Corporativa. Disponível em: http:// www.ibgc.org.br. Acesso em: 10 out. 2017.

MARINHO, S. M. M. Explorando os laços do capitalismo no Brasil: a forma e o conteúdo das estratégias de governança corporativa da BNDESPAR. Revista Direito GV, v. 14, n. 3, p. 847-885, 2019.

MATTOS, E. S.; RENZETTI, B. P. MAZALLI, R.; ERCOLIN, C. A. Governança corporativa. Rio de Janeiro: FGV, 2018

MORCK, R. K. A history of corporate governance around the world: Family business groups to professional managers. Chicago: University of Chicago Press, 2005. Disponível em: https://www.nber.org/books/ morc05-1. Acesso em: 10. Out. 2017. 
OECD - Organization for Economic Co-operation and Development. Using the OECD principles of corporate governance: A Boardroom perspective. Paris: OECD Publications, 2008. Disponível em: $\underline{\text { http:// }}$ www.oecd.org/corporate/ca/corporategovernanceprinciples/40823806.pdf. Acesso em: 25 fev. 2017.

SILVA, E. C. Governança Corporativa nas Empresas: guia prático de orientação para acionistas, investidores, conselheiros de administração e fiscal, auditores, executivos, gestores, analistas de mercado e pesquisadores. 3. ed. São Paulo: Editora Atlas, 2012.

SILVA, R. C. F. \& SEIBERT, R. M. Governança corporativa: história e tendências. Revista Interdisciplinar Científica Aplicada, v.9, n.3, p.76-101, 2015

SILVA, R. C. F. \& SEIBERT, R. M.. Governança: os diferentes mecanismos de controle para organizações com e sem fins lucrativos. Vivências: Revista Eletrônica de Extensão da URI, v. 12, p. 168-186, 2016

SILVA, R. L. M.; NARDI, P.C. C.; MARTINS, V. A. \& BAROSSI FILHO, M. Os níveis de governança corporativa da BM\&FBovespa aumentam a liquidez das ações? BASE - Revista de Administração e Contabilidade da UNISINOS, v. 13, n. 3, p. 248-263, 2016.

SILVA, P. Z. P.; ARAÚJO, V. R. B. S.; MONTE, P. A. Uma análise da pecking order theory nos diferentes níveis de governança corporativa da BM\&FBOVESPA. Revista Científica Hermes, v. 20, p. 153-176, 2018.

SUCHMAN, M. C. Managing legitimacy: strategic and institutional approaches. Academy of Management Review, v. 20, n. 3, p. 571-610, 1995.

VERGARA, S. C. Projetos e Relatórios de Pesquisa em Administração. 16. ed. São Paulo: Editora Atlas, 2016. 